\title{
Isolation and Characterization of Twenty Polymorphic Microsatellite Loci for Moringa oleifera (Moringaceae)
}

\author{
Jiang-Chong Wu and Jing Yang \\ Kunming Botanical Garden, Kunming Institute of Botany, Chinese Academy \\ of Sciences, Kunming 650204, China; and Graduate University of Chinese \\ Academy of Sciences, Beijing 100049, China

\section{Zhi-Jian Gu \\ Kunming Botanical Garden, Kunming Institute of Botany, Chinese Academy of Sciences, Kunming 650204, China}

\author{
Yan-Ping Zhang ${ }^{1}$ \\ Research Institute of Resource Insects, Chinese Academy of Forestry, \\ Kunming 650224, China
}

Additional index words. Horse radish tree, drumstick tree, SSR makers, population structure, population genetics

\begin{abstract}
By using a modified biotin-streptavidin capturing method, a total of 20 polymorphic microsatellite markers were developed from Moringa oleifera Lam. (Moringaceae), a useful multipurpose tree. Twenty-four domesticated individuals, with germplasms of India and Myanmar, were used to screen polymorphism of these 20 microsatellite markers. The number of alleles per locus ranged from two to six. The expected and observed heterozygosity varied from 0.3608 to 0.7606 and from 0.0000 to $\mathbf{0 . 8 7 5 0}$, respectively. Seven loci were significantly deviated from Hardy-Weinberg equilibrium. The availability of these microsatellite primers would provide a powerful tool for aspects of detailed population genetic studies of $M$. oleifera.
\end{abstract}

Moringa oleifera Lam. (synonym: $M$. ptreygosperma Gaertn.), an economically important multipurpose tree indigenous to northwest India, is the most widely cultivated, applied, and well-known one of all 13 species in the monogeneric family Moringaceae (Olson, 2002). Popularly known as "Drumstick" tree, horseradish tree, or Ben tree, $M$. oleifera is a deciduous-to-evergreen shrub or small tree with a height of 5 to $10 \mathrm{~m}$ (Morton, 1991). Its seedlings are fast-growing with early sexual maturity and a height up to $4.5 \mathrm{~m}$ in 9 months and flowering in half a year (Von Maydell, 1986). M. oleifera used to distribute wildly in the forests of Western

\footnotetext{
Received for publication 31 Dec. 2009. Accepted for publication 4 Feb. 2010.

This work was jointly funded by the Chinese Ministry of Science and Technology (2006BAD18 B03) and the Chinese Academy of Forestry (RIRICAF200805M).

We thank Chun-Yan Yang and Yuan Huang (Key Laboratory of Plant Biodiversity and Biogeography, Kunming Institute of Botany, Chinese Academy of Sciences) for their great help in technical guidance and preparing the manuscript. We also thank Ying-Chun Miao (Research Institute of Resource Insects, Chinese Academy of Forestry) for her helpful discussion.

${ }^{1}$ To whom reprint requests should be addressed; e-mail congongong@qq.com.
}

Himalaya (Hooker, 1879), and then throughout India by cultivation (Selvam, 2005).

Featured by richness in proteins, minerals, and vitamins, the leaves of $M$. oleifera are used as a highly nutrient vegetable and as cattle fodder (Mughal et al., 1999). In addition, the seed powder is used in water purification (Ndabigengesere and Narasiah, 1998), and the seed oil is acquired for edibles, lubrication, and cosmetics (Anwar and Bhanger, 2003). Because of its multiple applications and commercial benefits, $M$. oleifera has been broadly introduced and cultivated around the world, and has been identified as important in agri-horti-silviculture programs (Morton, 1991). It is commonly planted in hedges and house yards, especially intercropped in agroforestry systems, and it thrives in various subtropical and tropical regions (Selvam, 2005). Nevertheless, there is a deficient understanding of its detailed gene flow pattern and population genetic structure, which causes uncertainty in designing and managing seed orchards (Muluvi et al., 2004). Thus, the development of efficient molecular markers for M. oleifera is needed.

Based on codominant features and high allelic polymorphism, microsatellites [simple sequence repeats (SSRs)] have become a useful marker system in genetic diversity studies (Walter and Epperson, 2001) and paternity analysis (Chaix et al., 2003). In this article, 20 polymorphic microsatellite markers isolated and characterized from $M$. oleifera are reported for which no SSRs have been developed to date.

\section{Materials and Methods}

Seeds were introduced from Bangalore (India) and Pakokku (Myanmar). Leaf samples were collected from one-year-old plants with both germplasms in a small experimental population domesticated at Yuanjiang County in Yunnan Province, China $\left(23^{\circ} 32.580^{\prime} \mathrm{N}\right.$, $102^{\circ} 03.350^{\prime} \mathrm{E}$, elevation $\left.610 \mathrm{~m}\right)$. Genomic DNA samples were extracted using a DP320 DNAsecure Plant kit (Tiangen, China). The isolation of microsatellite loci was performed according to a modified enrichment protocol of fast isolation by AFLP of sequences containing repeats (FIASCO) (Zane et al., 2002). Briefly, about $250 \mathrm{ng}$ of genomic DNA was completely digested with $5 \mathrm{U}$ of $\mathrm{MseI}$ restriction enzyme (Fermantas, Canada) in a $20 \mu \mathrm{L}$ volume, and then $15 \mu \mathrm{L}$ of digested DNA was ligated to $1 \mu \mathrm{M}$ MseI amplified fragment length polymorphism (AFLP) adaptor pair (5'-TACTCAGGACTCAT-3'/5'-GAC GATGAGTCCTGAG-3') (Vos et al., 1995) with $2 \mathrm{U}$ of T4 DNA ligase (Fermantas, Canada) in a volume of $30 \mu \mathrm{L}$. In succession, $5 \mu \mathrm{L}$ of 1:10 diluted ligation products acting as templates were amplified with AFLP adaptor-specific primers MseI-N (5'-GATG AGTCCTGAGTAAN-3') in a $20 \mu \mathrm{L}$ reaction containing $\mathrm{MgCl}_{2} 1.5 \mathrm{~mm}, 1.25 \mu \mathrm{M}$ Mse I-N primers, $0.2 \mathrm{~mm} \mathrm{dNTPs}$, and $1 \mathrm{U}$ of Taq DNA polymerase (Biomed, China). The polymerase chain reaction (PCR) was performed following the procedure: $95{ }^{\circ} \mathrm{C}$ for $3 \mathrm{~min}, 20$ cycles of $94{ }^{\circ} \mathrm{C}$ for $30 \mathrm{~s}$, $53{ }^{\circ} \mathrm{C}$ for $60 \mathrm{~s}, 72{ }^{\circ} \mathrm{C}$ for $60 \mathrm{~s}$, followed by $72{ }^{\circ} \mathrm{C}$ for $5 \mathrm{~min}$.

For enrichment of the fragments containing SSRs, the PCR products, with a size range of 200 to $1000 \mathrm{bp}$, were denatured at $95^{\circ} \mathrm{C}$ for $5 \mathrm{~min}$ and were then hybridized with $5^{\prime}$ biotinylated probe $(\mathrm{AG})_{15}$ in a $250-\mu \mathrm{L}$ solution $(4.16 \times \mathrm{SSC}$ and $0.07 \% \mathrm{SDS})$ at $48^{\circ} \mathrm{C}$ for $2 \mathrm{~h}$. Hybridization products were selectively captured with $600 \mu \mathrm{L}$ of Streptavidin MagneSphere ${ }^{\circledR}$ Paramagnetic Particles (Promega, Madison, WI), which were prewashed in $150 \mu \mathrm{L}$ of $\mathrm{TEN}_{100}(10 \mathrm{~mm}$ Tris- $\mathrm{HCl}, 1 \mathrm{~mm}$ EDTA, and $100 \mathrm{~mm} \mathrm{NaCl}, \mathrm{pH}$ 7.5) for three times. The mixture was incubated at room temperature for $30 \mathrm{~min}$ with constant gentle agitation. Subsequently, the complex of streptavidin-coated beads and DNA hybridized to the biotinylated probe was separated from nonspecific DNA in a magnetic field with two washing steps, including three times in $500 \mu \mathrm{L}$ of $\mathrm{TEN}_{1000}(10 \mathrm{~mm}$ Tris- $\mathrm{HCl}, 1 \mathrm{~mm}$ EDTA, and $1 \mathrm{M} \mathrm{NaCl}, \mathrm{pH} 7.5$ ) for $8 \mathrm{~min}$, and then three times in $500 \mu \mathrm{L}$ of high stringency buffer $(0.2 \times \mathrm{SSC}$ and $0.1 \% \mathrm{SDS})$ for $5 \mathrm{~min}$. The separated target DNA fragments were released by incubating at $95{ }^{\circ} \mathrm{C}$ for $10 \mathrm{~min}$ twice, first in $100 \mu \mathrm{L}$ of TE $(10 \mathrm{~mm}$ Tris- $\mathrm{HCl}$ and $1 \mathrm{~mm}$ EDTA, pH 8.0), second in $50 \mu \mathrm{L}$ of denaturing solution $(12 \mu \mathrm{L}$ of $10 \mathrm{M} \mathrm{NaOH}$, $11.5 \mu \mathrm{L}$ of acetic acid, and $26.5 \mu \mathrm{L}$ of TE). 
Table 1. Characteristics of 20 polymorphic microsatellite loci in Moringa oleifera.

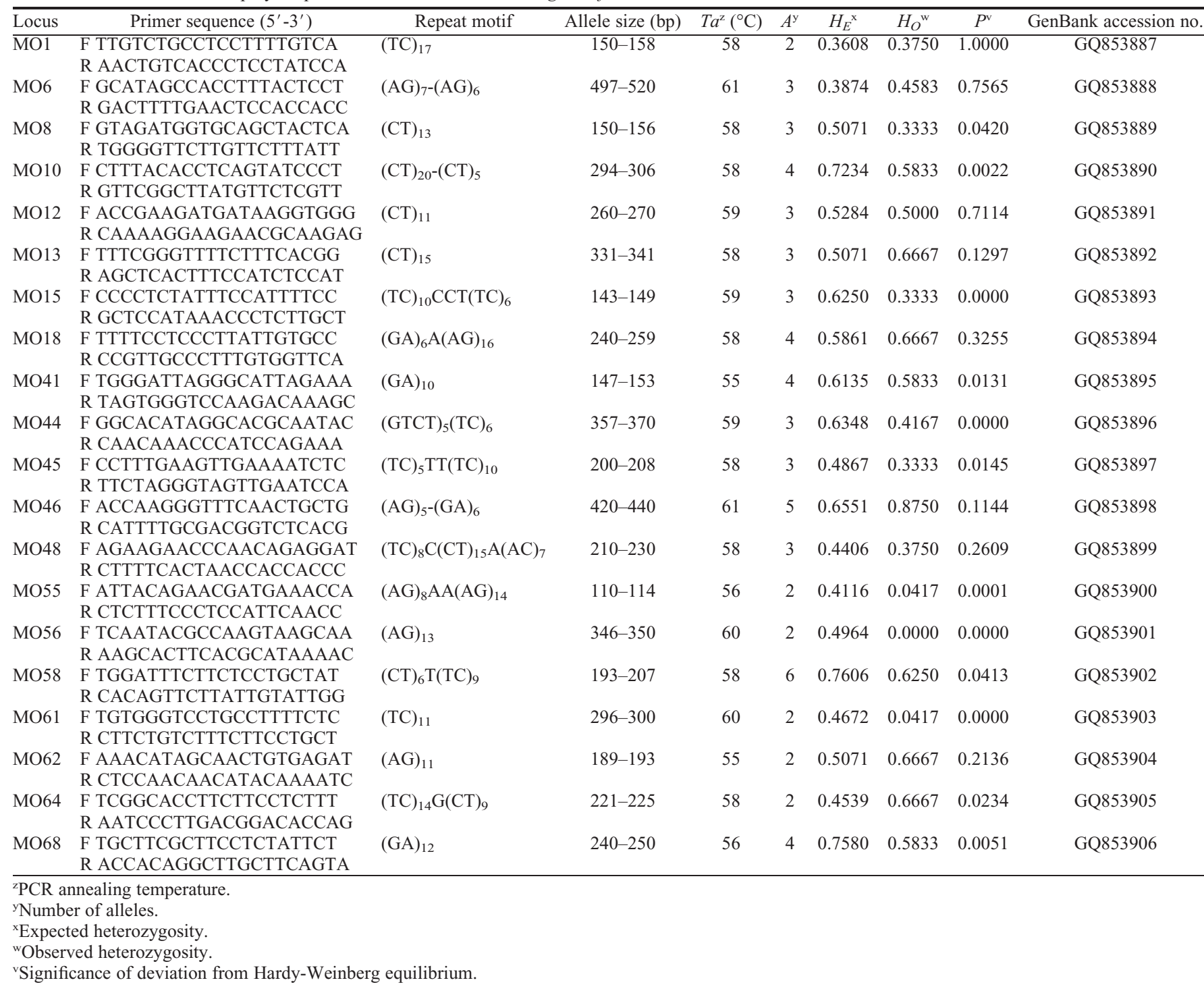

Recovered DNA was subjected to a second round of PCR with MseI-N primers according to the same procedure as the first round of PCR described above. The amplification products, after being purified with DP1502 multifunctional DNA purification and the recirculation kit (BioTeke, China), were directly ligated into PMD18-T vector (Takara, Japan) and then transformed into competent cells of Escherichia coli, strain DH5 $\alpha$ (Biomed, China). Clones were selected using blue/white selection after growth on IPTG-XGal media. The white clones were picked out and tested by means of PCR with a primer combination of $(\mathrm{AG})_{10}$ and $\mathrm{M}^{+} 3^{+}$

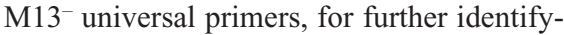
ing positive ones containing microsatellites. The insert fragments of positive clones were sequenced using an ABI 3730XL Genetic Analyzer (Applied Biosystems, Foster City, CA). After sequencing, primer pairs were designed based on the sequences flanking microsatellite repeats with Primer Premier 5.0 (Clarke and Gorley, 2001).

To assess polymorphism of designed primer pairs, $24 \mathrm{M}$. oleifera individuals (12 each with germplasms of India and Myanmar) in the experimental population were collected to screen polymorphism. PCR reaction was done in a $20-\mu \mathrm{L}$ volume using a PTC-100 thermal cycler (MJ Research, Cambridge, MA). Each reaction was performed using $25 \mathrm{ng}$ of genomic DNA, $1 \times$ buffer [with $20 \mathrm{~mm}$ Tris-HCl, pH 8.4, $20 \mathrm{~mm}$ $\mathrm{KCl}, 10 \mathrm{~mm}\left(\mathrm{NH}_{4}\right)_{2} \mathrm{SO}_{4}$, and $1.5 \mathrm{~mm} \mathrm{MgCl} 2$ ], $0.25 \mathrm{~mm}$ dNTP each, $0.5 \mu \mathrm{m}$ of each primer, and $1.5 \mathrm{U}$ of Taq DNA polymerase (Biomed). The PCR programs took place as follows: initial denaturing at $95^{\circ} \mathrm{C}$ for $5 \mathrm{~min}$, followed by 30 cycles of $94^{\circ} \mathrm{C}$ for $30 \mathrm{~s}$, primer-specific annealing temperature 55 to $61^{\circ} \mathrm{C}$ for $30 \mathrm{~s}$, $72{ }^{\circ} \mathrm{C}$ for $30 \mathrm{~s}$ and a final extension at $72{ }^{\circ} \mathrm{C}$ for $8 \mathrm{~min}$ and a hold at $4{ }^{\circ} \mathrm{C}$. The amplified products were then electrophoresed in $8 \%$ polyacrylamide gels and visualized by silver staining. Electrophoretic patterns were scored and checked with a 20-bp DNA ladder marker (Takara, Tokyo) used to estimate allele sizes.

Population genetic parameters were finally assessed. Allele numbers, expected $\left(H_{E}\right)$ and observed $\left(H_{O}\right)$ heterozygosities, and Hardy-
Weinberg equilibrium (HWE) were calculated by GENEPOP, version 3.4, on the web (http://genepop.curtin.edu.au/) (Raymond and Rousset, 1995). Tests for linkage disequilibrium between loci were run in FSTAT, version 2.9.3.2 (Goudet, 1995), with significance level adjusted by sequential Bonferroni corrections (Rice, 1989).

\section{Results and Discussion}

Screened by colony PCR, 210 of 288 randomly selected clones contained potential microsatellite motifs. After sequencing, 209 clones were successfully sequenced, and a total of 192 clones $(67 \%)$ were found to contain SSRs and were subjected to primer designing. In all, 69 pairs of 20-base primers were designed. Of these primers designed for M. oleifera, 46 pairs successfully amplified target regions and, finally, 20 pairs displayed polymorphism. Characteristics of these 20 loci are shown in Table 1. The number of alleles per locus ranged from two to six, with an average of three. The expected $\left(H_{E}\right)$ and observed $\left(H_{O}\right)$ heterozygosities ranged from 
0.3608 to 0.7606 (average of 0.5455 ) and from 0.0000 to 0.8750 (average of 0.4562 ), respectively. Significant departures from HWE were detected in all 20 loci, among which seven loci significantly deviated from HWE $(P<0.01)$, probably due to excess of homozygotes (suggesting inbreeding pressure) or the limitation of sample size. In addition, no locus pair showed significant linkage disequilibrium after Bonferroni correction.

The 20 pairs of polymorphic microsatellite primers presented here would be useful for aspects of detailed population genetic studies of $M$. oleifera. First, these markers are currently being used for the research of pollen-mediated gene flow within populations. Although outcrossing rate, an important parameter of mating systems, has been known for sure, randomization and minimum distance between related individuals needs to be worked out to maximize cross-fertilization among unrelated clones and to minimize selfing or mating among related ramets in designing $M$. oleifera seed orchards (Muluvi et al., 2004). With these microsatellite primers, paternity analysis of $M$. oleifera, involving pollen dispersal distance and gene flow pattern, would accumulate fundamental data for design and management of $M$. oleifera seed orchards. Moreover, these SSR primers would be helpful in revealing introduction traces and genetic components of introduced populations. Investigation by AFLP concluded that at least two sources of germplasm had been introduced to Kenya from India since the turn of 20th century (Muluvi et al., 1999). Now that $M$. oleifera has been used for over 100 years, information on genetic diversity levels and relatedness of introduced populations should be enriched more to further facilitate reasoned decisions on its selective breeding and conservation.

\section{Literature Cited}

Anwar, F. and M.I. Bhanger. 2003. Analytical characterization of Moringa oleifera seed oil grown in temperate regions of Pakistan. J. Agr. Food Chem. 51:6558-6563.

Chaix, G., S. Gerber, V. Razafimaharo, P. Vigneron, D. Verhaegen, and S. Hamon. 2003. Gene flow estimation with microsatellites in a Malagasy seed orchard of Eucalyptus grandis. Theor. Appl. Genet. 107:705-712.

Clarke, K.R. and R.N. Gorley. 2001. PRIMER v5: User manual/tutorial. PRIMER-E Ltd., Plymouth, UK.

Goudet, J. 1995. FSTAT (Version 1.2): A computer program to calculate f-statistics. J. Hered. $86: 485-486$

Hooker, J.D. 1879. The flora of British India. Vol. II. L. Reeve \& Co., London, UK

Morton, J.F. 1991. The horseradish tree, Moringa pterigosperma (Moringaceae): A boon to arid lands? Econ. Bot. 45:318-333.

Mughal, M.H., P.S. Saba-Srivastava, and M. Iqbal. 1999. Drumstick (Moringa pterygsperma Gaertn.): A unique source of food and medicine. J. Econ. Taxon. Bot. 23:47-61.

Muluvi, G.M., J.I. Sprent, D. Odee, and W. Powell. 2004. Estimates of outcrossing rates in Moringa oleifera using amplified fragment length polymorphism (AFLP). Afr. J. Biotechnol. 3: 146-151.
Muluvi, G.M., J.I. Sprent, N. Soranzo, J. Provan, D. Odee, G. Folkard, J.W. McNicol, and W. Powell. 1999. Amplified fragment length polymorphism (AFLP) analysis of genetic variation in Moringa oleifera Lam. Mol. Ecol. 8:463-470.

Ndabigengesere, A. and K.S. Narasiah. 1998. Quality of water treated by coagulation using Moringa oleifera seeds. Water Res. 32:781791.

Olson, M.E. 2002. Combining data from DNA sequences and morphology for a phylogeny of Moringaceae (Brassicales). Syst. Bot. 27:5573.

Raymond, M. and F. Rousset. 1995. GENEPOP (Version 1.2): Population genetics software for exact tests and ecumenicism. J. Hered. 86:248249.

Rice, W.R. 1989. Analyzing tables of statistical tests. Evolution 43:223-225.

Selvam, A.B.D. 2005. Distribution, phenology and utilization of Moringa oleifera Lamk.: An indigenous medicinal plant of India. J. Econ. Taxon. Bot. 29:102-108.

Von Maydell, H.J. 1986. Trees and shrubs of sahel: Their characterization and uses. Deutsche Gesellschaft fur Technische Zusammenarbeit, Eschborn, Germany. p. 334-337.

Vos, P., R. Hogers, M. Bleeker, M. Reijans, T. van de Lee, M. Hornes, A. Frijters, J. Pot, J. Peleman, M. Kuiper, and M. Zabeau. 1995. AFLP: A new technique for DNA fingerprinting. Nucleic Acids Res. 23:4407-4414.

Walter, R. and B.K. Epperson. 2001. Geographic pattern of genetic variation in Pinus resinosa: Area of greatest diversity is not the origin of postglacial populations. Mol. Ecol. 10:103-111.

Zane, L., L. Bargelloni, and T. Patarnello. 2002. Strategies for microsatellite isolation: A review. Mol. Ecol. 11:1-16. 